\title{
High Glucose Induces Sumoylation of Smad4 via SUMO2/3 in Mesangial Cells
}

\author{
Xueqin Zhou, ${ }^{1,2}$ Chenlin Gao, ${ }^{1}$ Wei Huang, ${ }^{1}$ Maojun Yang, ${ }^{1}$ Guo Chen, \\ Lan Jiang, ${ }^{1}$ Fang Gou, ${ }^{1}$ Hong Feng, ${ }^{1} \mathrm{Na} \mathrm{Ai},{ }^{1}$ and Yong $\mathrm{Xu}^{1}$ \\ ${ }^{1}$ Department of Endocrinology, Affiliated Hospital of Luzhou Medical College, Luzhou, Sichuan 646000, China \\ ${ }^{2}$ Department of Endocrinology, The Central Hospital of Bazhong City, Sichuan 636000, China
}

Correspondence should be addressed to Yong Xu; xywyll@aliyun.com

Received 27 February 2014; Accepted 1 May 2014; Published 27 May 2014

Academic Editor: Keizo Kanasaki

Copyright (C) 2014 Xueqin Zhou et al. This is an open access article distributed under the Creative Commons Attribution License, which permits unrestricted use, distribution, and reproduction in any medium, provided the original work is properly cited.

Recent studies have shown that sumoylation is a posttranslational modification involved in regulation of the transforming growth factor- $\beta$ (TGF- $\beta$ ) signaling pathway, which plays a critical role in renal fibrosis in diabetic nephropathy (DN). However, the role of sumoylation in the regulation of TGF- $\beta$ signaling in DN is still unclear. In the present study, we investigated the expression of SUMO (SUMO1 and SUMO2/3) and Smad4 and the interaction between SUMO and Smad4 in cultured rat mesangial cells induced by high glucose. We found that SUMO1 and SUMO2/3 expression was significantly increased in the high glucose groups compared to the normal group $(P<0.05)$. Smad4 and fibronectin $(\mathrm{FN})$ levels were also increased in the high glucose groups in a dose-dependent manner. Coimmunoprecipitation and confocal laser scanning revealed that Smad4 interacted and colocalized with SUMO2/3, but not with SUMO1 in mesangial cells. Sumoylation (SUMO2/3) of Smad4 under high glucose condition was strongly enhanced compared to normal control $(P<0.05)$. These results suggest that high glucose may activate TGF- $\beta /$ Smad signaling through sumoylation of Samd 4 by SUMO2/3 in mesangial cells.

\section{Introduction}

Diabetic nephropathy (DN) is a serious microvascular complication of diabetes and a leading cause of end-stage renal disease in developed countries. Early DN is characterized by mesangial expansion, thickened glomerular and tubular basement membranes, and accumulation of the extracellular matrix (ECM) and can progress to glomerulosclerosis and tubulointerstitial fibrosis in later stages [1-3]. At present, the pathogenesis of DN remains unclear, and then further study of molecular mechanisms to develop new treatment approaches for $\mathrm{DN}$ is required.

As a key mediator of fibrogenesis, transforming growth factor- $\beta$ (TGF- $\beta$ ) plays a critical role in diabetic nephropathy, and Smad4 is a common mediator in TGF- $\beta$ signaling [4-6]. The TGF- $\beta /$ Smad pathway is modulated by several posttranslational modifications, including phosphorylation, ubiquitination, and acetylation $[7,8]$. In a previous study, we demonstrated that ubiquitination of histones $\mathrm{H} 2 \mathrm{~A}$ and $\mathrm{H} 2 \mathrm{~B}$ is involved in diabetic nephropathy by activating the TGF- $\beta$ signaling pathway [9]. Recent studies have demonstrated that sumoylation is a reversible posttranslational modification involved in regulation of the TGF- $\beta$ signaling pathway $[10$, 11].

SUMO is a type of small ubiquitin-like molecule primarily involved in posttranslational modification of proteins, similar to ubiquitination. In mammals, there are four SUMO paralogues, SUMO1, SUMO2, SUMO3, and SUMO4 [12]. SUMO2 and SUMO3 share 95\% homology with each other and are collectively referred to as SUMO2/3 [13]. Sumoylation is the covalent attachment of SUMO to specific target proteins via an ATP-dependent enzyme cascade, including E1 activating enzyme, E2 conjugating enzyme (Ubc9), and several E3 ligases [14]. Sumoylation plays an important role in multiple biological processes, such as protein interactions, protein stability, nuclear-cytoplasmic trafficking, transcriptional regulation, DNA repair, and cellular signaling pathways $[15,16]$. Recent studies have shown that sumoylation 
regulates the TGF- $\beta$ pathway by modifying several important signaling molecules, such as type I TGF- $\beta$ receptor (T $\beta$ RI) and Smad4 [17]. However, whether sumoylation is involved in the pathogenesis of DN is unknown.

In this study, we detected the levels of SUMO and Smad in each group to investigate whether they were regulated by high glucose and whether high glucose could induce sumoylation of Smad4 in rat mesangial cells. And we explored the role of sumoylation in regulating TGF- $\beta /$ Smad signaling in DN.

\section{Materials and Methods}

2.1. Cell Culture. Rat glomerular mesangial cells (HBZY1) were purchased from the Preservation Center at Wuhan University and cultured in low glucose DMEM (Hyclone) medium with $10 \%$ fetal bovine serum (FBS, Invitrogen) and $1 \%$ penicillin/streptomycin. Mesangial cells were cultured with serum free medium for $24 \mathrm{~h}$ before treatment, followed by addition of $5.6 \mathrm{mmol} / \mathrm{L}$ glucose as a normal control, 10, 20, and $30 \mathrm{mmol} / \mathrm{L}$ glucose as experimental groups, and mannitol as an osmotic control for $6 \mathrm{~h}, 12 \mathrm{~h}$, and 24 h.

2.2. Cell Lysis and Western Blotting. Cells were washed three times with ice-cold phosphate-buffered saline (PBS) and lysed in lysis buffer $(3.0 \mathrm{M} \mathrm{NaCl}, 1.0 \mathrm{M}$ Tris $\mathrm{PH} 7.5,1 \%$ TritonX-100, 10\% SDS and protease inhibitor). Cell lysates were centrifuged at $4^{\circ} \mathrm{C}, 15,000 \times \mathrm{g}$ for $10 \mathrm{~min}$ to pellet cell debris and protein samples were extracted. Supernatants were separated on SDS-PAGE and transferred onto PVDF membranes (Millipore). Membranes were blocked in 5\% nonfat milk for $1 \mathrm{~h}$ and incubated with primary antibodies overnight at $4^{\circ} \mathrm{C}$. Primary antibodies included mouse monoclonal antiSmad4 (1:500, Santa Cruz), rabbit polyclonal anti-SUMO2/3 (1:600, Millipore), rabbit monoclonal anti-SUMO1 $(1: 800$, Abcam), and mouse monoclonal anti-GAPDH $(1: 1,000$, Beyotime Biotechnology). Membranes were incubated with horseradish peroxidase-linked anti-mouse and anti-rabbit secondary antibodies (Beyotime) at room temperature for $1 \mathrm{~h}$. Proteins were detected using ECL reagents (Millipore) and the Bio-Rad chemiluminescence system and quantitatively analyzed by Quantity One software.

2.3. Immunoprecipitation and Immunoblotting. Cells were lysed in ice-cold IP lysis buffer $(150 \mathrm{mM} \mathrm{NaCl}, 25 \mathrm{mM}$ Tris PH 7.4, $1 \mathrm{mM}$ EDTA, 1\% NP-40, 5\% glycerol and protease inhibitor). Cell lysates were centrifuged at $15,000 \times \mathrm{g}$ at $4^{\circ} \mathrm{C}$ for $15 \mathrm{~min}$, and the supernatants were subjected to immunoprecipitation with mouse anti-Smad4 antibody or mouse IgG as negative control overnight at $4^{\circ} \mathrm{C}$. Immune complexes were precipitated with protein $\mathrm{G}$ agarose beads for $1-2 \mathrm{~h}$ under rotary agitation, and the agarose beads were washed four times in wash buffer. Bound proteins were eluted in $2 \mathrm{x}$ reducing sample buffer, and samples were analyzed by Western blotting as described using mouse anti-Smad 4 antibody for Smad4 and rabbit anti-SUMO1 or SUMO2/3 antibody for SUMO-conjugated Smad4 protein.
2.4. Reverse Transcription-PCR. Cells were washed twice in ice-cold PBS and lysed in TRIzol reagent, followed by total RNA extraction using the RNAsimple Total RNA kit (Tiangen Biotech). Samples were reverse transcribed (RT) to cDNA using a kit according to the manufacturer's instructions (Bio-BRK). PCR was performed using the cDNA and the following primers: SUMO1, forward $5^{\prime}$-TATGGACAGGACAGCAG-3', reverse $5^{\prime}$-CCATTCCCAGTTCTTTT G3'; SUMO2/3, forward 5'-GACGAGAAACCCAAGGA-3', reverse $5^{\prime}$-CTGCCGTTCACAATAGG-3'; FN, forward $5^{\prime}$ CAGCCTACGGATGACTC- $3^{\prime}$, reverse $5^{\prime}$-CTCTTTCTGCCACTGTTCT-3'; and GAPDH, forward $5^{\prime}$-GGTCATGAGTCCTTCCACGATA-3', reverse $5^{\prime}$-ATGCTGGCGCTGAGTACGTC-3' . PCR products were analyzed using $2 \%$ agarose gels and visualized by a UV transilluminator.

2.5. Immunofluorescence. Mesangial cells were grown on coverslips in 6-well plates. Cells were fixed in $4 \%$ paraformaldehyde (Pierce) and permeabilized in $0.25 \%$ Triton X-100 (Sigma) for $10 \mathrm{~min}$. Cells were washed twice in PBS and blocked in $5 \%$ goat serum for $1 \mathrm{~h}$ at room temperature, followed by incubation with anti-Smad 4 and anti-SUMO2/3 antibodies overnight at $4^{\circ} \mathrm{C}$. After washing, cells were incubated with rhodamine and fluorescein isothiocyanateconjugated secondary antibodies (Bio-Synthesis) for $45 \mathrm{~min}$ in the dark. The coverslips were washed and mounted onto slides using mounting medium (Beyotime) and imaged with a DMIRE2 laser scanning confocal microscope (Leica, Germany).

2.6. Statistical Analyses. All data obtained from at least three independent experiments were expressed as the mean \pm standard deviation (SD) and analyzed using one-way analysis of variance (ANOVA), followed by the LSD post hoc test for multiple comparisons (SPSS 11.5 statistical software). $P<$ 0.05 was considered significant.

\section{Results}

3.1. High Glucose Induced SUMO1 and SUMO2/3 Expression in Mesangial Cells. To determine whether SUMO is regulated by glucose in mesangial cells, we first detected SUMO proteins by Western blot. As shown in Figure 1(a) SUMO1 and SUMO2/3 expression in mesangial cells gradually increased after treatment with $30 \mathrm{mmol} / \mathrm{L}$ glucose for $12 \mathrm{~h}$ to $24 \mathrm{~h}$ and was highest at $24 \mathrm{~h}$. There was no significant increase at $6 \mathrm{~h}$ compared to the normal control. SUMO1 and SUMO2/3 were highly expressed in the high glucose groups, particularly in the $20 \mathrm{mmol} / \mathrm{L}$ glucose group, compared to normal control $(P<0.05$, Figure $1(\mathrm{~b}))$. A significant difference was found between the mannitol and normal control groups. However, the expressions of SUMO1 and SUMO2/3 were significantly decreased in the mannitol group compared with the $20 \mathrm{mmol} / \mathrm{L}$ and $30 \mathrm{mmol} / \mathrm{L}$ glucose groups $(P<0.05)$, suggesting that osmotic pressure had a little effect on the high glucose-induced SUMO expression. Reverse transcriptionPCR (RT-PCR) was performed to assess glucose-induced 


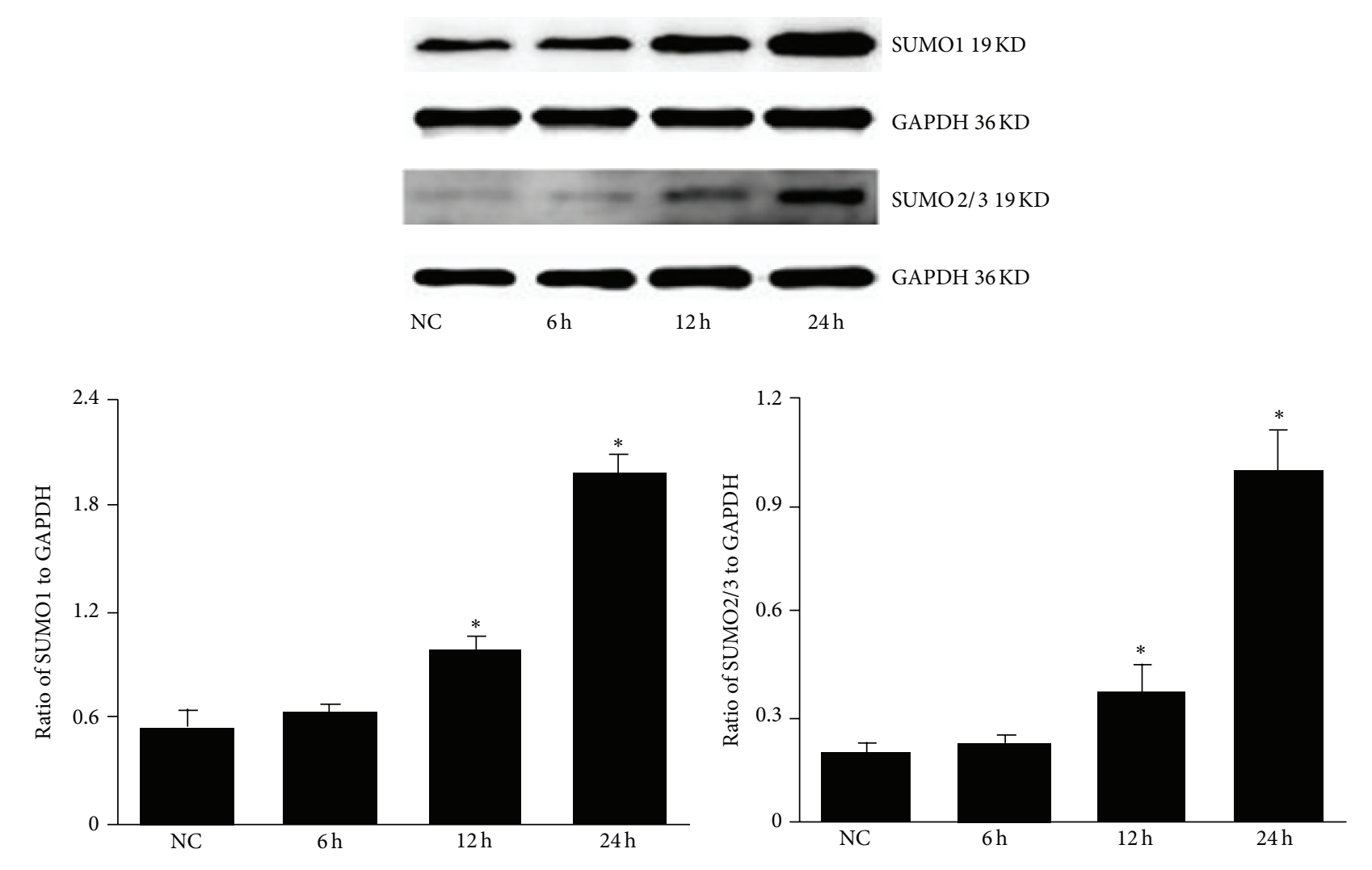

(a)

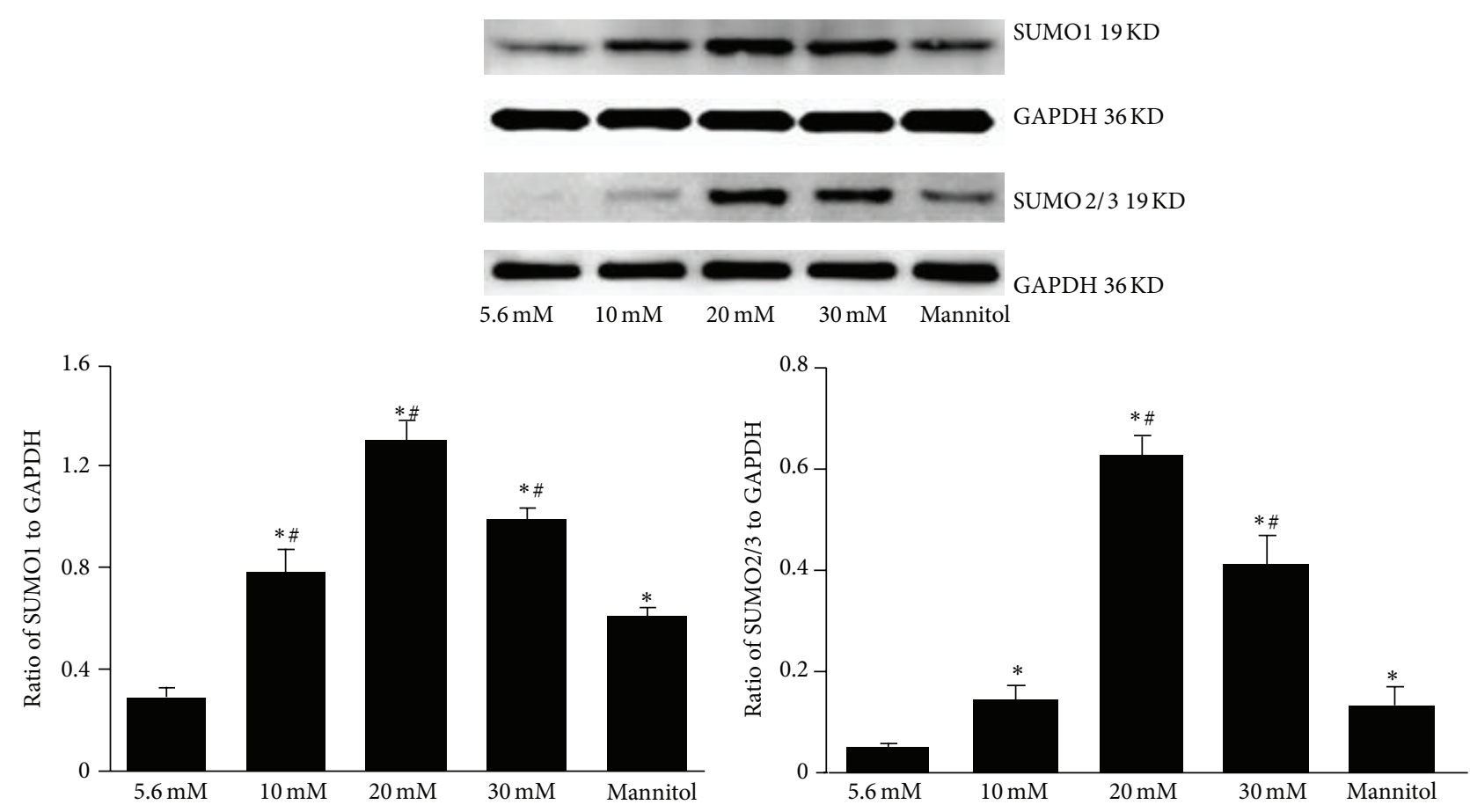

(b)

FIGURE 1: SUMO protein expression in mesangial cells detected by Western blot. (a) Cells were treated with $30 \mathrm{mmol} / \mathrm{L}$ high glucose for 6, 12, and $24 \mathrm{~h}$, and Western blot was performed to detect SUMO1 and SUMO2/3 protein levels. ${ }^{*} \mathrm{P}<0.05$ compared to normal control (NC) group. (b) Cells were treated with the indicated concentrations of glucose or mannitol for $24 \mathrm{~h}$, with $5.6 \mathrm{mmol} / \mathrm{L}$ glucose as a normal control and $30 \mathrm{mmol} / \mathrm{L}$ mannitol as an osmotic control. ${ }^{*} \mathrm{P}<0.05$ compared to normal control; ${ }^{\#} \mathrm{P}<0.05$ compared to mannitol control. GAPDH was used as a loading control in (a) and (b). 

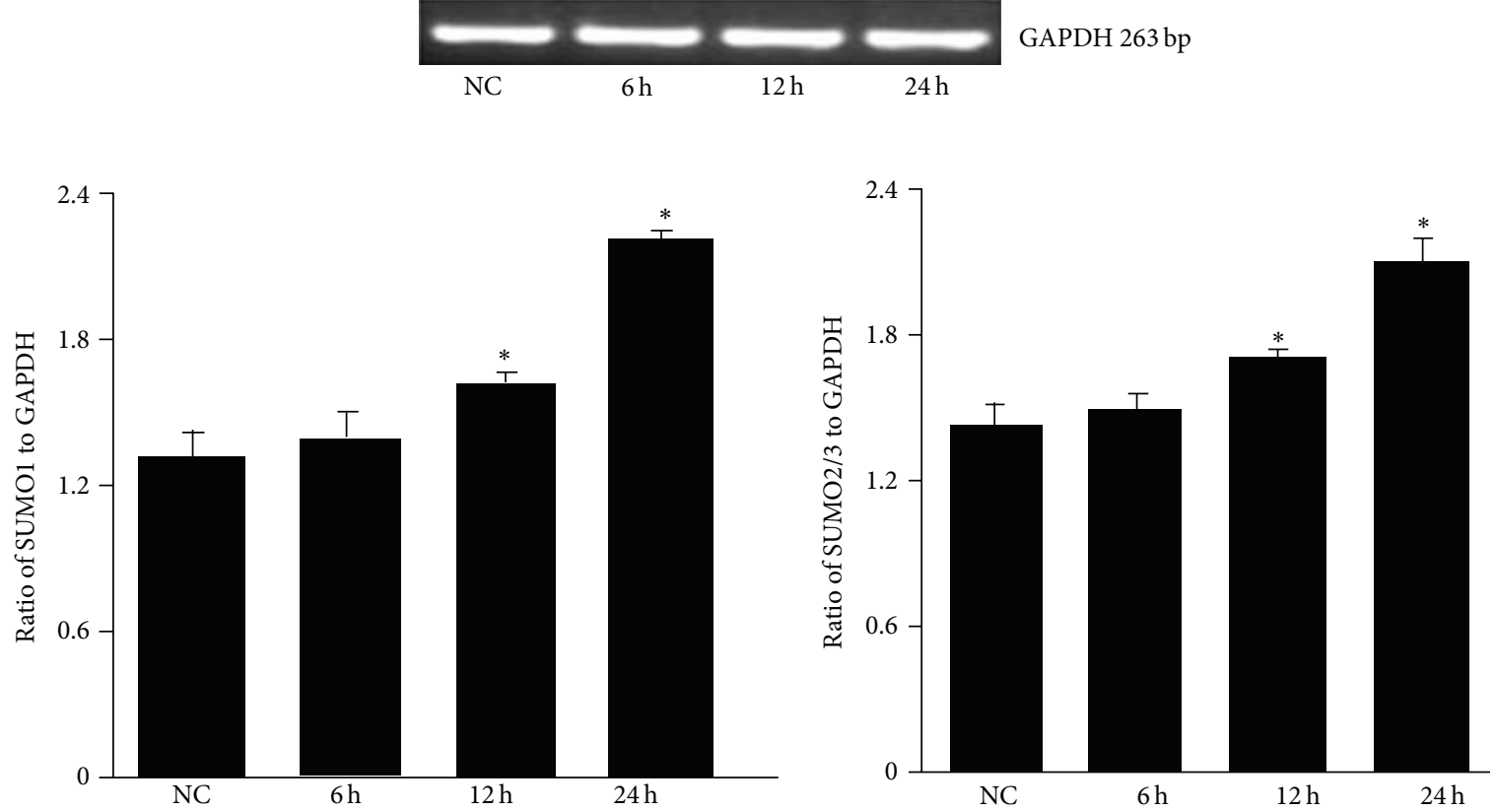

(a)

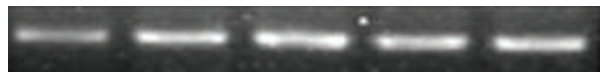

SUMO1 $170 \mathrm{bp}$

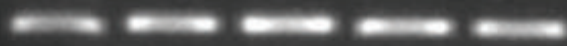

SUMO2/3 $147 \mathrm{bp}$
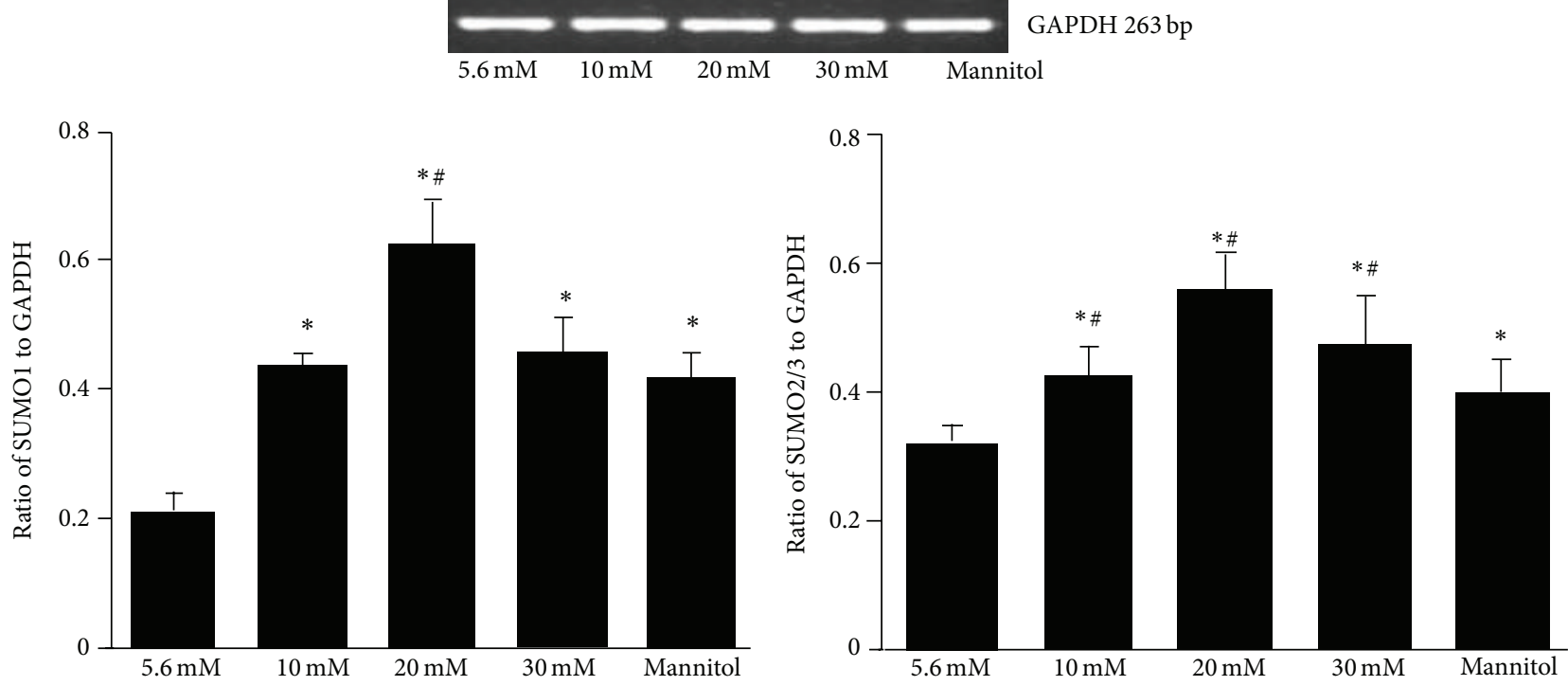

(b)

FIGURE 2: Reverse transcription-PCR analysis of SUMO mRNA expression. (a) Mesangial cells were treated with $30 \mathrm{mmol} / \mathrm{L}$ high glucose for 6,12 , and $24 \mathrm{~h}$. SUMO1 and SUMO2/3 mRNA levels were assessed by RT-PCR and normalized to GAPDH. ${ }^{*} \mathrm{P}<0.05$ compared to normal control (NC) group. (b) Cells were treated with the indicated concentrations of glucose or mannitol for $24 \mathrm{~h}$, with $5.6 \mathrm{mmol} / \mathrm{L}$ glucose as a normal control and $30 \mathrm{mmol} / \mathrm{L}$ mannitol as an osmotic control. GAPDH was used to confirm equal loading. ${ }^{*} P<0.05$ compared to normal control; ${ }^{\#} P<0.05$ compared to mannitol control. 


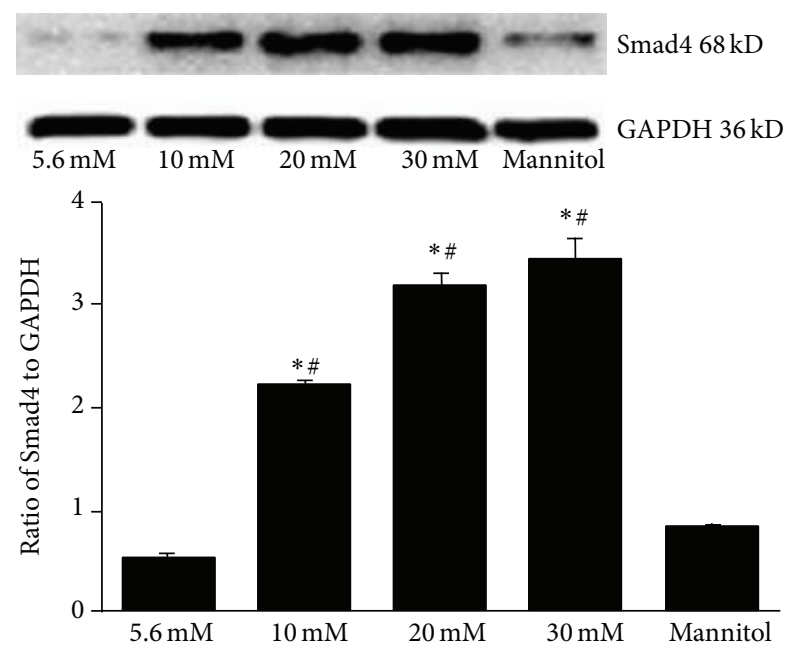

FIGURE 3: Smad4 protein expression in mesangial cells induced by high glucose. Mesangial cells were treated with the indicated concentrations of glucose or mannitol for $24 \mathrm{~h}$, and Western blot was performed to detect Smad4 protein levels with $5.6 \mathrm{mmol} / \mathrm{L}$ glucose as a normal control and $30 \mathrm{mmol} / \mathrm{L} \mathrm{mannitol}$ as an osmotic control. ${ }^{*} P<0.05$ compared to normal control; ${ }^{\#} P<0.05$ compared to mannitol control.

SUMO1 and SUMO2/3 mRNA expression. Results showed similar trend with SUMO protein expression (Figure 2).

\subsection{High Glucose Induces Smad4 Expression in Mesangial} Cells. Western blot was used to detect Smad4 protein levels in mesangial cells exposed to glucose or mannitol for $24 \mathrm{~h}$. GAPDH was used as a loading control. As shown in Figure 3, Smad4 was abundantly expressed in the high glucose groups in a concentration dependent manner compared to normal control. In addition, there was no significant difference between the mannitol osmotic and normal controls, confirming that glucose, but not osmotic stress, increased Smad4 expression in mesangial cells.

3.3. Smad4 is Sumoylated by SUMO2/3 in Mesangial Cells. To determine whether Smad4 is sumoylated in mesangial cells, cell lysates were subjected to immunoprecipitation with antiSmad4 antibody. Normal mouse IgG was used as a control antibody and immunoprecipitates were immunoblotted with anti-SUMO2/3 or anti-SUMO1 antibodies. An approximately $90 \mathrm{kDa}$ band representing SUMO2/3-Smad4 conjugates was detected, and its size was compatible with the addition of a single SUMO2/3 molecule to Smad4 (Figure 4(a)). In contrast, the mouse IgG control antibody did not detect sumoylated Smad4 protein. Figure 4(b) shows that a specific band for SUMO1-Smad4 conjugated protein (about $90 \mathrm{kDa}$ ) was not detected, indicating that Smad4 is not sumoylated by SUMO1 in mesangial cells. To further assess high glucose-induced sumoylation of Smad4, anti-Smad4 immunoprecipitates were immunoblotted with anti-Smad4 or anti-SUMO2/3 antibodies after treating mesangial cells with various concentrations of glucose or mannitol for $24 \mathrm{~h}$. As shown in Figure 4(c), a SUMO2/3-Smad4 conjugated protein was strongly expressed in the $20 \mathrm{mmol} / \mathrm{L}$ glucose group compared to normal and mannitol controls $(P<0.01)$. These results suggest that high glucose but not osmotic stress activates sumoylation of Smad4 via SUMO2/3 in mesangial cells.

3.4. Colocalization of SUMO2/3 and Smad4 in Mesangial Cells. Immunofluorescence was performed to determine subcellular localization of SUMO2/3 and Smad4 after mesangial cells were treated with high glucose for $24 \mathrm{~h}$. Cells were incubated with anti-Smad4 and anti-SUMO2/3 primary antibodies and stained with fluorescein isothiocyanate and rhodamine-conjugated secondary antibodies. Under confocal immunofluorescence microscopy, Smad4 showed diffuse cytoplasmic and nuclear distribution (Figures 5(a), 5(d), and $5(\mathrm{~g})$ ), while SUMO2/3 was localized primarily in the nucleus with a punctated pattern in each group (Figures 5(b), $5(\mathrm{e})$, and 5(h)). The merged images showed that SUMO2/3 colocalized with Smad4 primarily in the nucleus and was strongly enhanced in the high glucose group (Figure 5(f)) compared with normal (Figure 5(c)) and mannitol controls (Figure 5(i)).

\subsection{High Glucose Induced Fibronectin (FN) mRNA Expression} in Mesangial Cells. Fibronectin (FN) is an ECM protein in diabetic kidney. RT-PCR analysis of FN mRNA in mesangial cells showed that the expression of FN mRNA increased in high glucose groups compared to the normal control group $(P<0.05)$ in a concentration and time dependent manner (Figure 6). A significant difference between the mannitol and normal control groups was observed. However, the expression of FN mRNA was lower in the mannitol group compared with the $20 \mathrm{mmol} / \mathrm{L}$ and $30 \mathrm{mmol} / \mathrm{L}$ glucose groups $(P<0.05$; Figure $6(\mathrm{~b}))$, indicating that high glucoseinduced the increase of FN mRNA expression was not an osmotic effect.

\section{Discussion}

TGF- $\beta$ has been considered a key mediator in multiple organ fibrosis, including the heart, liver, lung, and kidney [18-20]. TGF- $\beta$ signaling is transduced by transmembrane receptors (T $\beta$ RII, T $\beta$ RI) and intracellular signals called Smads (Smad18) [21]. Hyperglycemia, AGE, and angiotensin II have been shown to activate TGF- $\beta$ signaling in mesangial and tubular cells $[5,6]$. Diabetic glomerulosclerosis and tubulointerstitial fibrosis are caused by accumulation of ECM proteins and glomerular basement membrane thickening [22, 23]. FN is one of the major components of the ECM and is useful in evaluating pathological conditions in DN [24]. Our data show that high glucose increased the expression of FN in mesangial cells, further confirming that high glucose promotes the fibrosis in DN.

Many studies have indicated that phosphorylation and activation of $S \operatorname{mad} 2 / 3$ contribute to diabetic renal fibrosis [25, 26]. However, the role of Smad4 in TGF- $\beta$-mediated renal fibrosis is largely unclear. Therefore, we investigated whether Smad4 is regulated by high glucose in cultured mesangial 


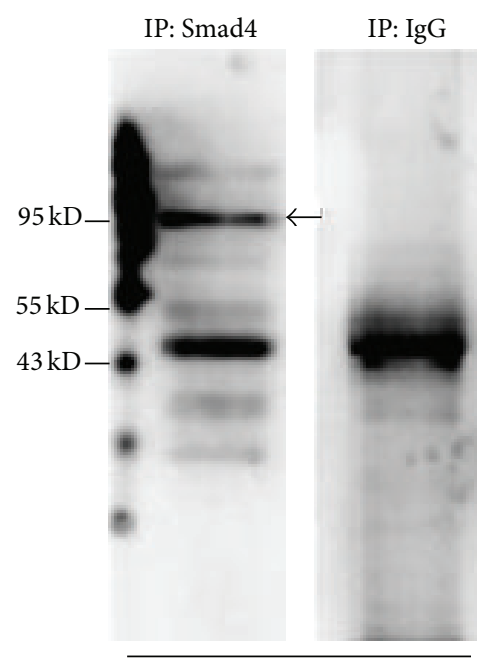

IB: SUMO2/3
SUMO2/3-Smad4

IgG-H

(a)

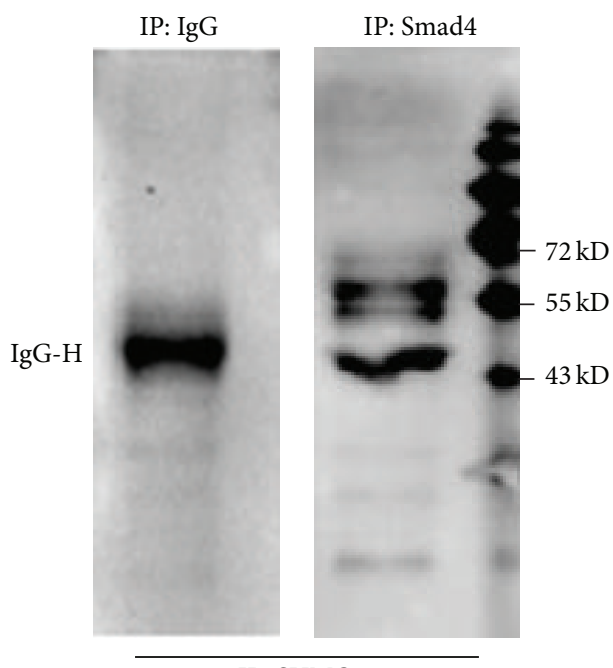

IB: SUMO1

IP: Smad 4
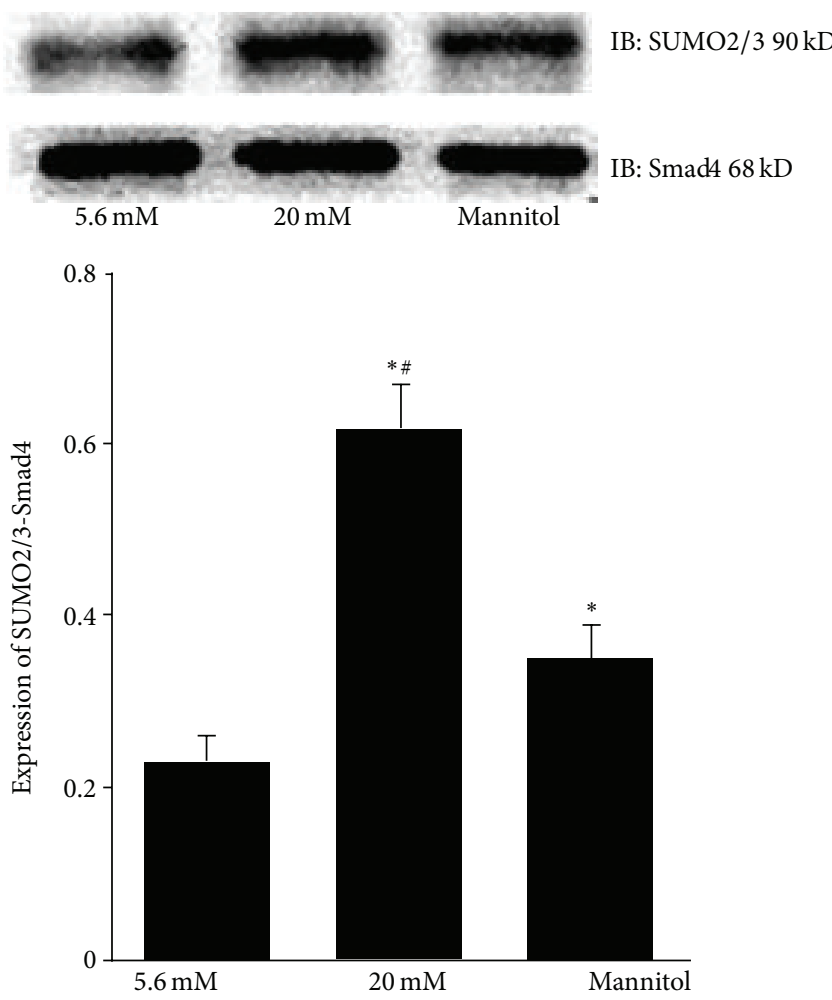

(c)

FIGURE 4: Smad4 is sumoylated by SUMO2/3 in mesangial cells. (a) and (b) Cell lysates were subjected to immunoprecipitation (IP) with anti-Smad4 antibody or normal mouse IgG as a negative control, followed by immunoblot (IB) with anti-SUMO2/3 or anti-SUMO1 antibody to detect the interaction between SUMO2/3 or SUMO1 with Smad4. The arrow marked band indicates SUMO2/3-Smad4 conjugates (a). No specific band was detected for SUMO1-Smad4 conjugates in mesangial cells (b). IgG-H marks the IgG heavy chain in (a) and (b). (c) Cells were treated with $5.6 \mathrm{mmol} / \mathrm{L}$ and $20 \mathrm{mmol} / \mathrm{L}$ glucose and equimolar concentration of mannitol for $24 \mathrm{~h}$. Anti-Smad 4 immunoprecipitates were subjected to immunoblotting with anti-Smad4 or anti-SUMO2/3 antibodies for Smad4 and SUMO2/3-Smad4 proteins. Relative expression of SUMO2/3-Smad4 conjugates was detected by Western blot and normalized to Smad4. ${ }^{*} P<0.05$ compared to normal control; ${ }^{\#} P<0.05$ compared to mannitol control. 


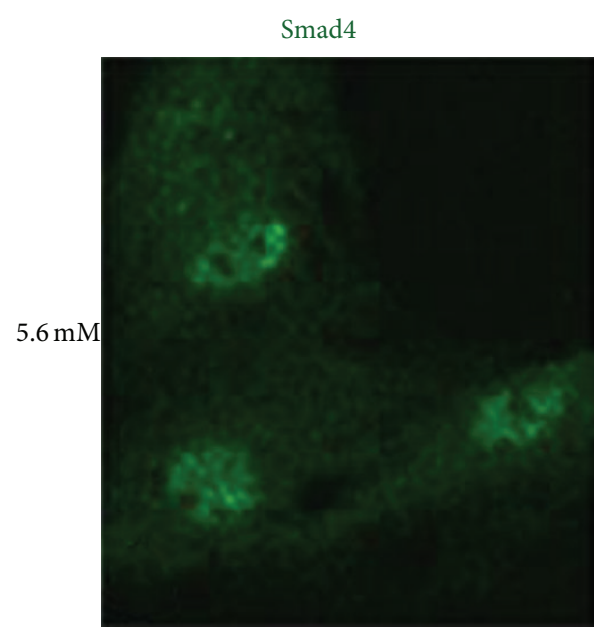

(a)

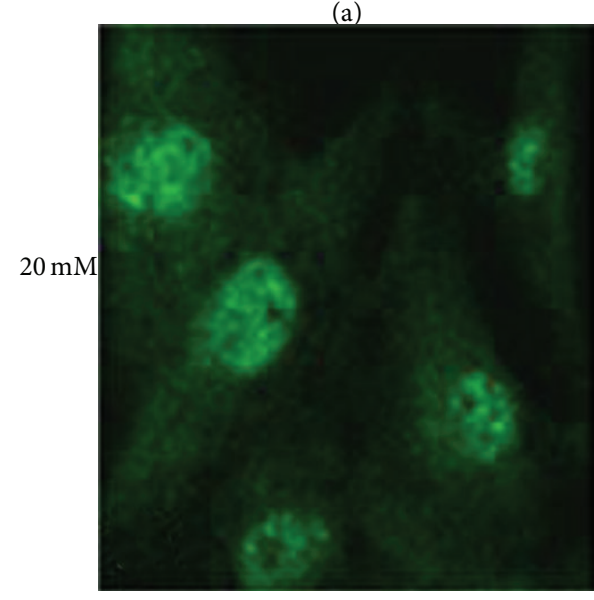

(d)

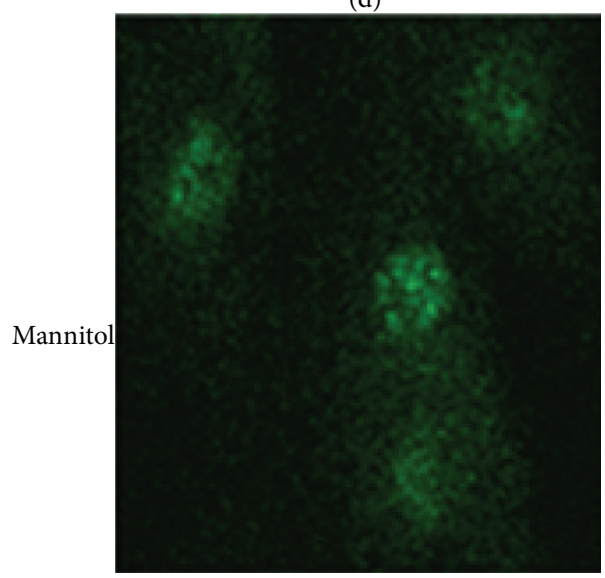

(g)
SUMO2/3

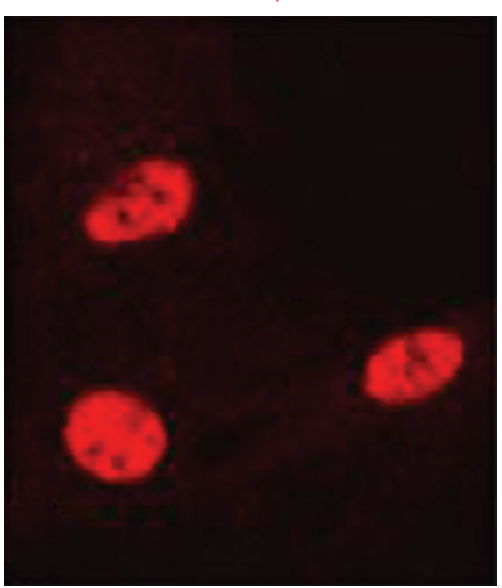

(b)

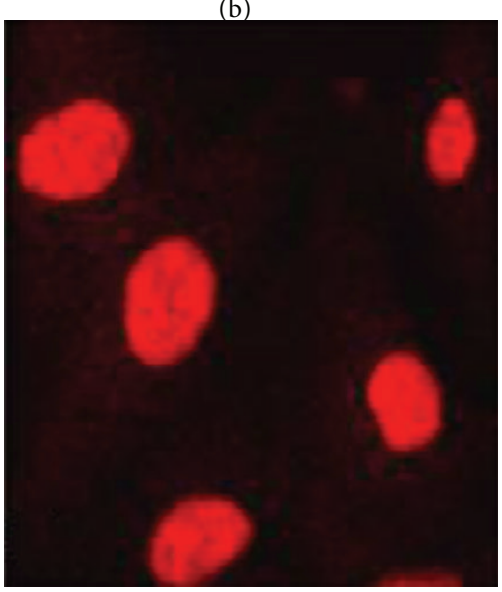

(e)

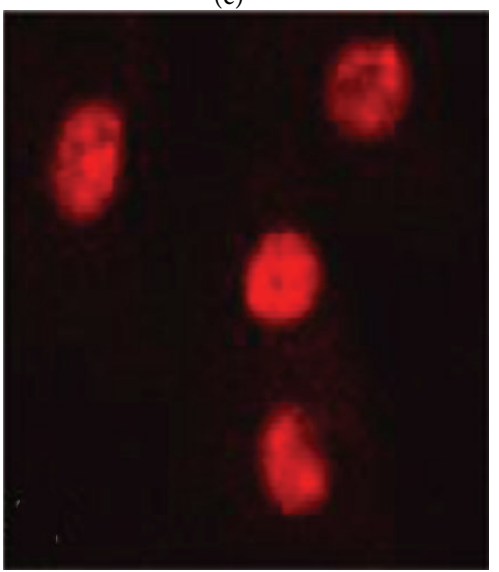

(h)
Merge

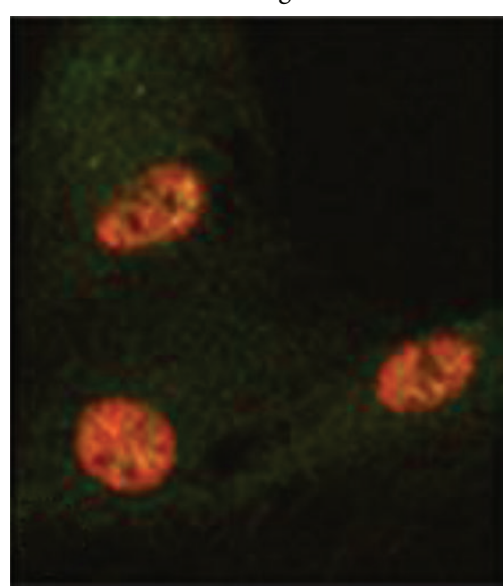

(c)

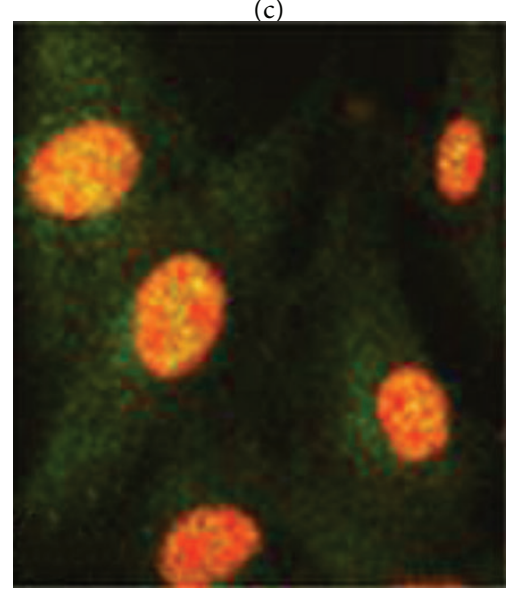

(f)

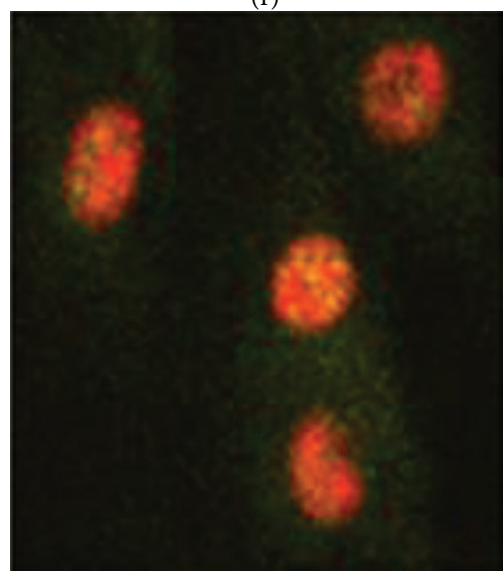

(i)

FIGURE 5: Colocalization of SUMO2/3 and Smad4 in mesangial cells. Cells were incubated with mouse anti-Smad4 monoclonal antibody and rabbit anti-SUMO2/3 polyclonal antibody and visualized with fluorescein isothiocyanate-conjugated anti-mouse IgG for Smad4 ((a), (d), (g)) and rhodamine-conjugated anti-rabbit IgG for SUMO2/3 ((b), (e), (h)). The merged images of Smad 4 and SUMO2/3 stainings in each group are shown in (c), (f), and (i).

cells. As expected, our results showed that high glucose increased Smad4 expression in a concentration dependent manner, indicating that Smad4 is positively involved in TGF$\beta$-mediated progression of $\mathrm{DN}$. This finding is similar to that of Meng et al. [27], who revealed that deletion of Smad4 inhibited progression of renal fibrosis.
Our previous study showed that ubiquitination of histones $\mathrm{H} 2 \mathrm{~A}$ and $\mathrm{H} 2 \mathrm{~B}$ could activate the TGF- $\beta$ signaling pathway in diabetic nephropathy [9]. However, several studies have suggested that use of the specific ubiquitin proteasome inhibitor MG132 cannot completely block activation of the TGF- $\beta$ signaling pathway $[28,29]$. This indicates that other 

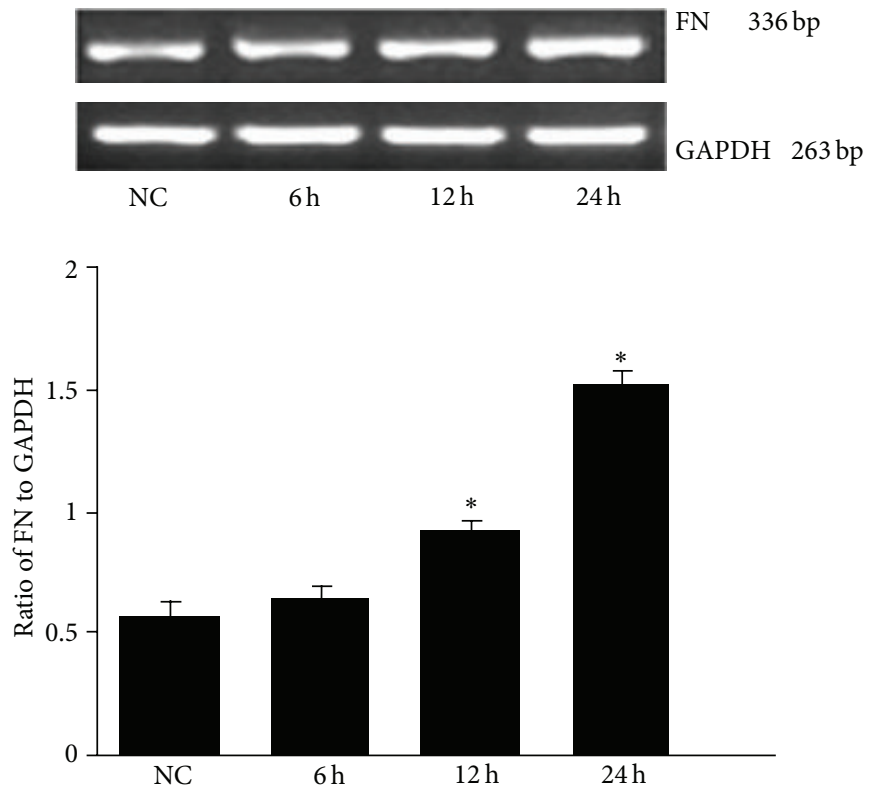

(a)
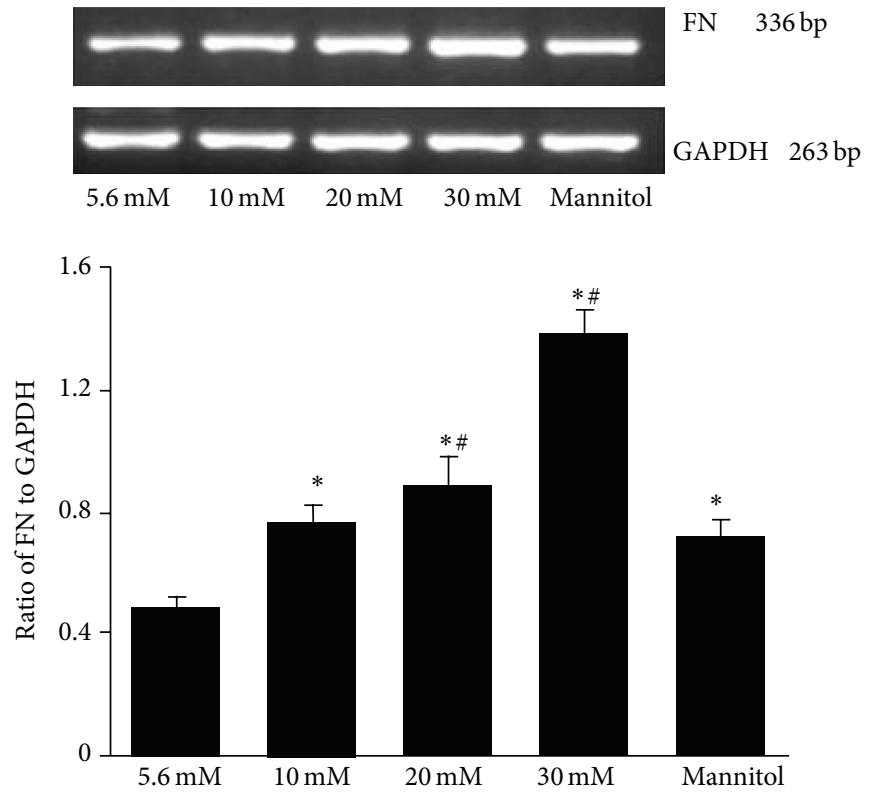

(b)

FIGURE 6: Reverse transcription-PCR analysis of FN mRNA expression in mesangial cells. (a) Mesangial cells were treated with 30 mmol/L high glucose for 6,12 , and $24 \mathrm{~h}$, and FN mRNA expression levels were detected by RT-PCR. ${ }^{*} P<0.05$ compared to normal control (NC) group. (b) Cells were treated with different concentrations of glucose or mannitol for $24 \mathrm{~h}$, with $5.6 \mathrm{mmol} / \mathrm{L}$ glucose as a normal control and $30 \mathrm{mmol} / \mathrm{L}$ mannitol as an osmotic control. ${ }^{*} P<0.05$ compared to normal control; ${ }^{\#} P<0.05$ compared to mannitol control.

protein modifications are also involved in TGF- $\beta$ pathway activation in DN. For example, sumoylation has been demonstrated to play an important role in a wide range of biological processes and several human diseases, such as inflammation, cancer, heart disease, and neurodegenerative diseases [30-33]. However, it is not known whether sumoylation is involved in DN.
SUMO1 and SUMO2/3 are expressed in most tissues, whereas SUMO4 expression appears to be limited to the kidney, lymph node, and spleen [34]. In addition, various cellular stresses, such as osmotic, oxidative stress, and heat shock, have been shown to increase sumoylation by SUMO2/3 but have little effect on SUMO1 modification. Interestingly, a previous study reported that $\mathrm{M} 55 \mathrm{~V}$ substitution in the 
SUMO4 gene $(163 \mathrm{~A} \rightarrow \mathrm{G})$ was strongly associated with type 1 diabetes [35]. To determine whether SUMOs are expressed and regulated by glucose in mesangial cells, we used Western blot and RT-PCR for detection. Our data show that SUMO1 and SUMO2/3 are expressed in mesangial cells, and high glucose increased the expression of SUMO. Meanwhile, we found that osmotic stress had little effect on the expression of SUMO1 and SUMO2/3 compared with high glucose. These results suggest that SUMO1 and SUMO2/3 may be involved in the progression of DN. The detailed mechanisms involved will require further study.

More than 120 SUMO substrate proteins have been identified. The majority are nuclear proteins, and most of nonnuclear substrates are signal transduction proteins, including NEMO, I $\kappa \mathrm{B} \alpha$, Smads, Glut 4 , and T $\beta \mathrm{RI}[36,37]$. Sumoylation changes the activity, subcellular localization, or stability of these proteins to influence signal transduction [15]. Sumoylation has been demonstrated to regulate the canonical TGF- $\beta /$ Smad pathway through T $\beta$ RI, Smad3, and Smad4 $[10,11,38]$. Several studies have shown that Smad4 is sumoylated by SUMO1 or SUMO2/3. Interestingly, these findings indicate an opposite effect of sumoylation on Smad4 activity, which can play a positive [39-41] or negative [42] role in regulating TGF- $\beta /$ Smad signaling.

Given the important role of sumoylation in the TGF$\beta /$ Smad pathway and previously described results, we hypothesized that sumoylation of Smad4 may have a role in TGF- $\beta$-mediated DN. Therefore, we determined whether Smad4 is sumoylated and the effect of high glucose on covalent modification. As expected, our data showed that Smad4 interacted and colocalized with SUMO2/3 in mesangial cells and the expression was strongly enhanced by glucose, and osmotic stress has been shown to have little effect on sumoylation by SUMO2/3. Unfortunately, we found that Smad4 is not sumoylated by SUMO1 in mesangial cells. The results suggest that high glucose stimulates sumoylation of Smad 4 through SUMO2/3 but not SUMO1 in mesangial cells, resulting in activation of the TGF- $\beta$ signaling pathway. The mechanisms involved may include the sumoylation of Smad4, preventing the degradation of Smad4, increasing the level of Smad4, and enhancing nuclear accumulation and stability of Smad4. We did not analyze other regulators, such as several R-Smads and TGF- $\beta$ receptors in this study. Additional studies are necessary to explore the diverse roles of sumoylation in TGF- $\beta /$ Smad signaling, which mediates pathogenesis of DN.

A recent in vivo study first reported that inhibition of sumoylation by knockdown of Ubc9 suppresses canonical TGF- $\beta /$ Smad signaling and prevents development of fibrosis in systemic sclerosis [43]. Netherton and Bonni reported that sumoylation plays an important role in TGF $\beta$-induced epithelial mesenchymal transition (EMT), which contributes to fibrotic and neoplastic diseases [44]. Moreover, another study demonstrated that sumoylation was involved in the progression of glomerulonephritis by regulating $\alpha$-smooth muscle actin transcription in mesangial cells [45]. All of these findings suggest that sumoylation may be a new therapeutic target for fibrotic diseases and is likely to provide new insights into the pathogenesis of these diseases.
In summary, our study found that high glucose significantly increased the expression of SUMO1 and SUMO2/3 and stimulated Smad4 sumoylation through SUMO2/3 but not SUMO1. We demonstrated that sumoylation of Smad4 may be involved in the pathogenesis of DN by regulating the TGF$\beta /$ Smad signaling pathway. Further studies on sumoylation will be necessary to find potential therapeutic targets for DN.

\section{Conflict of Interests}

The authors declare that they have no conflict of interests regarding the publication of this paper.

\section{Acknowledgments}

The authors gratefully acknowledge Neurobiology Laboratory, Clinical Center Laboratory, and Cordis-Myoelectricity Laboratory for technical assistance.

\section{References}

[1] F. P. Schena and L. Gesualdo, "Pathogenetic mechanisms of diabetic nephropathy," Journal of the American Society of Nephrology, vol. 16, supplement 3, pp. S30-S33, 2005.

[2] B. Najafian, C. E. Alpers, and A. B. Fogo, "Pathology of human diabetic nephropathy," Contributions to Nephrology, vol. 170, pp. 36-47, 2011.

[3] F. C. Brosius III, "New insights into the mechanisms of fibrosis and sclerosis in diabetic nephropathy," Reviews in Endocrine and Metabolic Disorders, vol. 9, no. 4, pp. 245-254, 2008.

[4] D. Pohlers, J. Brenmoehl, I. Löffler et al., “TGF- $\beta$ and fibrosis in different organs-molecular pathway imprints," Biochimica et Biophysica Acta, vol. 1792, no. 8, pp. 746-756, 2009.

[5] H. Y. Lan, "Transforming growth factor- $\beta /$ Smad signalling in diabetic nephropathy," Clinical and Experimental Pharmacology and Physiology, vol. 39, no. 8, pp. 731-738, 2012.

[6] S. Yamagishi, Y. Inagaki, T. Okamoto, S. Amano, K. Koga, and M. Takeuchi, "Advanced glycation end products inhibit de novo protein synthesis and induce TGF- $\beta$ overexpression in proximal tubular cells," Kidney International, vol. 63, no. 2, pp. 464-473, 2003.

[7] Y. Inoue and T. Imamura, "Regulation of TGF- $\beta$ family signaling by E3 ubiquitin ligases," Cancer Science, vol. 99, no. 11, pp. 2107-2112, 2008.

[8] M. L. Burch, W. Zheng, and P. J. Little, "Smad linker region phosphorylation in the regulation of extracellular matrix synthesis," Cellular and Molecular Life Sciences, vol. 68, no. 1, pp. 97-107, 2011.

[9] C. Gao, G. Chen, L. Liu et al., "Impact of high glucose and proteasome inhibitor MG132 on histone $\mathrm{H} 2 \mathrm{~A}$ and $\mathrm{H} 2 \mathrm{~B}$ ubiquitination in rat glomerular mesangial cells," Journal of Diabetes Research, vol. 2013, Article ID 589474, 10 pages, 2013.

[10] J. S. Kang, E. F. Saunier, R. J. Akhurst, and R. Derynck, "The type I TGF- $\beta$ receptor is covalently modified and regulated by sumoylation," Nature Cell Biology, vol. 10, no. 6, pp. 654-664, 2008.

[11] P. S. Lee, C. Chang, D. Liu, and R. Derynck, "Sumoylation of Smad4, the common Smad mediator of transforming growth factor- $\beta$ family signaling," Journal of Biological Chemistry, vol. 278, no. 30, pp. 27853-27863, 2003. 
[12] Z. Hannoun, S. Greenhough, E. Jaffray, R. T. Hay, and D. C. Hay, "Post-translational modification by SUMO," Toxicology, vol. 278, no. 3, pp. 288-293, 2010.

[13] K. I. Kim and S. H. Baek, "Chapter 7 small ubiquitin-like modifiers in cellular malignancy and metastasis," International Review of Cell and Molecular Biology C, vol. 273, pp. 265-311, 2009.

[14] K. A. Wilkinson and J. M. Henley, "Mechanisms, regulation and consequences of protein SUMOylation," Biochemical Journal, vol. 428, no. 2, pp. 133-145, 2010.

[15] Y. E. Wang, O. Pernet, and B. Lee, "Regulation of the nucleocytoplasmic trafficking of viral and cellular proteins by ubiquitin and small ubiquitin-related modifiers," Biology of the Cell, vol. 104, no. 3, pp. 121-138, 2012.

[16] J. Wang, "Cardiac function and disease: emerging role of small ubiquitin-related modifier," Wiley Interdisciplinary Reviews: Systems Biology and Medicine, vol. 3, no. 4, pp. 446-457, 2011.

[17] K. Miyazono, Y. Kamiya, and K. Miyazawa, "SUMO amplifies TGF- $\beta$ signalling," Nature Cell Biology, vol. 10, no. 6, pp. 635637, 2008.

[18] P. Teekakirikul, S. Eminaga, O. Toka et al., "Cardiac fibrosis in mice with hypertrophic cardiomyopathy is mediated by nonmyocyte proliferation and requires Tgf- $\beta$," Journal of Clinical Investigation, vol. 120, no. 10, pp. 3520-3529, 2010.

[19] T. Nakamura, R. Sakata, T. Ueno, M. Sata, and H. Ueno, "Inhibition of transforming growth factor $\beta$ prevents progression of liver fibrosis and enhances hepatocyte regeneration in dimethylnitrosamine- treated rats," Hepatology, vol. 32, no. 2, pp. 247-255, 2000.

[20] A. Biernacka, M. Dobaczewski, and N. G. Frangogiannis, "TGF$\beta$ signaling in fibrosis," Growth Factors, vol. 29, no. 5, pp. 196202, 2011.

[21] C. H. Heldin and A. Moustakas, "Role of Smads in TGF $\beta$ signaling," Cell and Tissue Research, vol. 347, no. 1, pp. 21-36, 2012.

[22] Y. S. Kanwar, J. Wada, L. Sun et al., "Diabetic nephropathy: mechanisms of renal disease progression," Experimental Biology and Medicine, vol. 233, no. 1, pp. 4-11, 2008.

[23] H. Y. Lan and A. C. Chung, "Transforming growth factor-beta and Smads," Contributions to Nephrology, vol. 170, no. 1, pp. 7582, 2011.

[24] M. Kanauchi, H. Nishioka, and K. Dohi, "Diagnostic significance of urinary fibronectin in diabetic nephropathy," Nihon Jinzo Gakkai Shi, vol. 37, no. 1, pp. 127-133, 1995.

[25] Y. Furuse, N. Hashimoto, M. Maekawa et al., "Activation of the Smad pathway in glomeruli from a spontaneously diabetic rat model, OLETF rats," Nephron-Experimental Nephrology, vol. 98, no. 3, pp. e100-e108, 2004.

[26] K. Inazaki, Y. Kanamaru, Y. Kojima et al., "Smad3 deficiency attenuates renal fibrosis, inflammation, and apoptosis after unilateral ureteral obstruction," Kidney International, vol. 66, no. 2, pp. 597-604, 2004.

[27] X. M. Meng, X. R. Huang, J. Xiao et al., "Disruption of Smad4 impairs TGF-B/Smad3 and Smad7 transcriptional regulation during renal inflammation and fibrosis in vivo and in vitro," Kidney International, vol. 81, no. 3, pp. 266-279, 2012.

[28] T. Sakairi, K. Hiromura, S. Takahashi et al., "Effects of proteasome inhibitors on rat renal fibrosis in vitro and in vivo," Nephrology, vol. 16, no. 1, pp. 76-86, 2011.

[29] Y. Takiyama, T. Harumi, J. Watanabe et al., “Tubular injury in a rat model of type 2 diabetes is prevented by metformin: a possible role of HIF- $1 \alpha$ expression and oxygen metabolism," Diabetes, vol. 60, no. 3, pp. 981-992, 2011.

[30] I. Paddibhatla, M. J. Lee, M. E. Kalamarz, R. Ferrarese, and S. Govind, "Role for sumoylation in systemic inflammation and immune homeostasis in Drosophila larvae," PLoS Pathogens, vol. 6, no. 12, Article ID e1001234, 2010.

[31] K. Bettermann, M. Benesch, S. Weis, and J. Haybaeck, "SUMOylation in carcinogenesis," Cancer Letters, vol. 316, no. 2, pp. 113125, 2012.

[32] J. Wang and R. J. Schwartz, "Sumoylation and regulation of cardiac gene expression," Circulation Research, vol. 107, no. 1, pp. 19-29, 2010.

[33] J. S. Steffan, N. Agrawal, J. Pallos et al., "SUMO modification of Huntingtin and Huntington's disease pathology," Science, vol. 304, no. 5667, pp. 100-104, 2004.

[34] E. Meulmeester and F. Melchior, “Cell biology: SUMO," Nature, vol. 452, no. 7188, pp. 709-711, 2008.

[35] D. Guo, M. Li, Y. Zhang et al., "A functional variant of SUMO4, a new I kappa B alpha modifier, is associated with type 1 diabetes," Nature Genetics, vol. 36, no. 8, pp. 837-841, 2004.

[36] J. Zhao, "Sumoylation regulates diverse biological processes," Cellular and Molecular Life Sciences, vol. 64, no. 23, pp. 30173033, 2007.

[37] H. Lomelí and M. Vázquez, "Emerging roles of the SUMO pathway in development," Cellular and Molecular Life Sciences, vol. 68, no. 24, pp. 4045-4064, 2011.

[38] S. Imoto, K. Sugiyama, R. Muromoto, N. Sato, T. Yamamoto, and T. Matsuda, "Regulation of transforming growth factor- $\beta$ signaling by protein inhibitor of activated STAT, PIASy through Smad3," Journal of Biological Chemistry, vol. 278, no. 36, pp. 34253-34258, 2003.

[39] X. Lin, M. Liang, Y. Liang, F. C. Brunicardi, F. Melchior, and $\mathrm{X}$. Feng, "Activation of transforming growth factor- $\beta$ signaling by SUMO-1 modification of tumor suppressor Smad4/DPC4," Journal of Biological Chemistry, vol. 278, no. 21, pp. 18714-18719, 2003.

[40] M. Liang, F. Melchior, X. Feng, and X. Lin, "Regulation of Smad4 sumoylation and transforming growth factor- $\beta$ signaling by protein inhibitor of activated STAT1," Journal of Biological Chemistry, vol. 279, no. 22, pp. 22857-22865, 2004.

[41] X. Lin, M. Liang, Y. Liang, F. C. Brunicardi, and X. Feng, "SUMO-1/Ubc9 promotes nuclear accumulation and metabolic stability of tumor suppressor Smad4," Journal of Biological Chemistry, vol. 278, no. 33, pp. 31043-31048, 2003.

[42] J. Long, G. Wang, H. E. Dongming, and F. Liu, "Repression of Smad4 transcriptional activity by SUMO modification," Biochemical Journal, vol. 379, no. 1, pp. 23-29, 2004.

[43] A. Khodzhigorova, A. Distler, V. Lang et al., "Inhibition of sumoylation prevents experimental fibrosis," Annals of the Rheumatic Diseases, vol. 71, no. 11, pp. 1904-1908, 2012.

[44] S. J. Netherton and S. Bonni, "Suppression of TGF $\beta$-induced epithelial-mesenchymal transition like phenotype by a PIAS1 regulated sumoylation pathway in NMuMG epithelial cells," PLoS ONE, vol. 5, no. 11, Article ID e13971, 2010.

[45] K. Torikoshi, H. Abe, T. Matsubara et al., "Protein inhibitor of activated stat, piasy regulates $\alpha$-smooth muscle actin expression by interacting with e12 in mesangial cells," PLOS ONE, vol. 7, no. 7, Article ID e41186, 2012. 


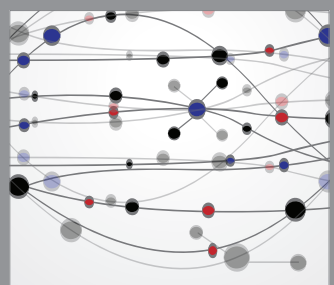

The Scientific World Journal
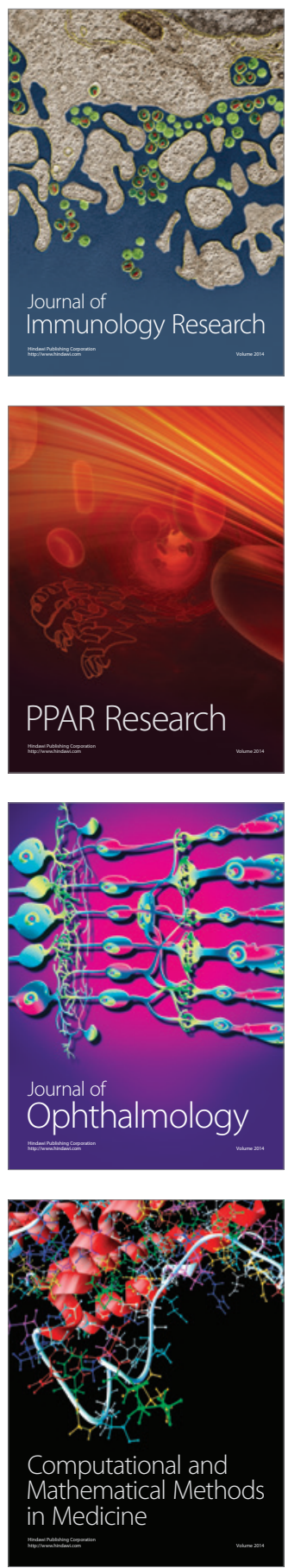

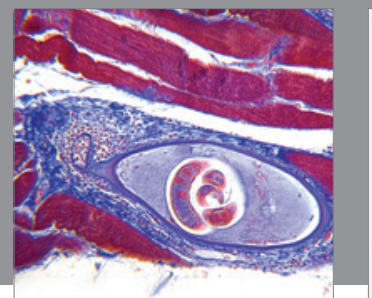

Gastroenterology

Research and Practice
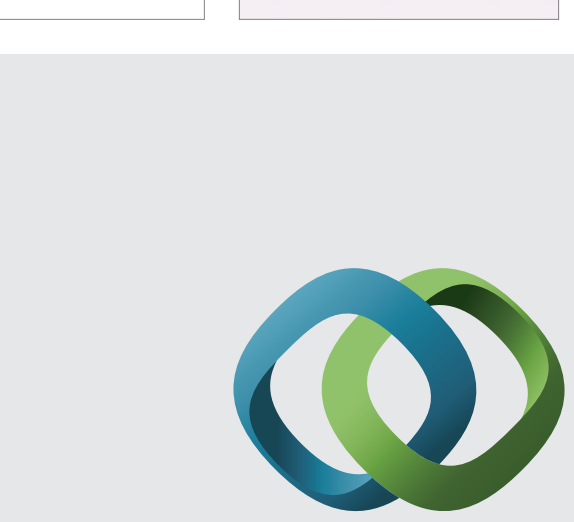

\section{Hindawi}

Submit your manuscripts at

http://www.hindawi.com
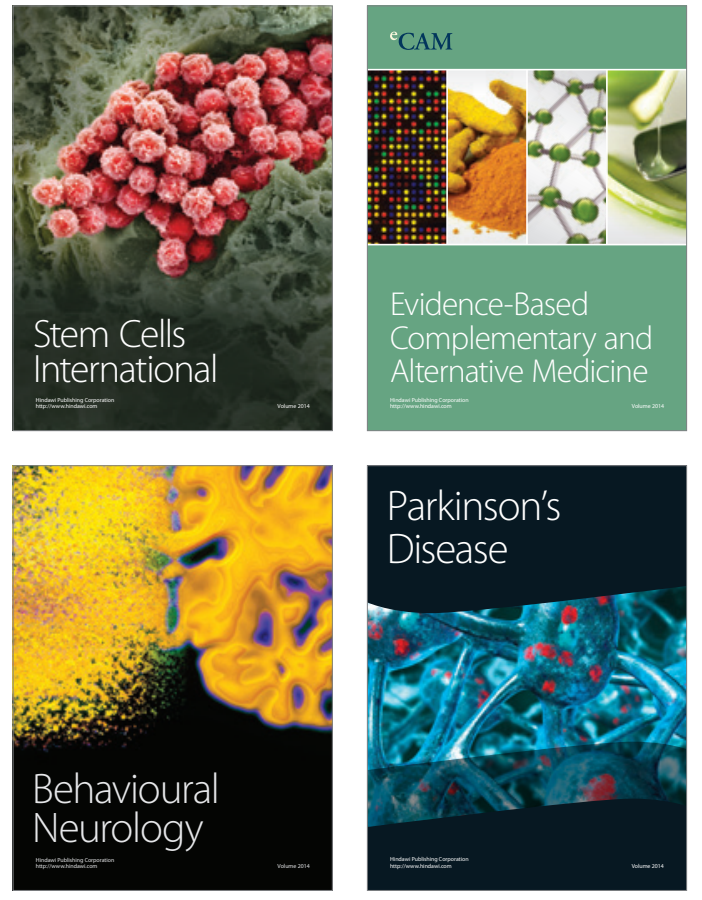
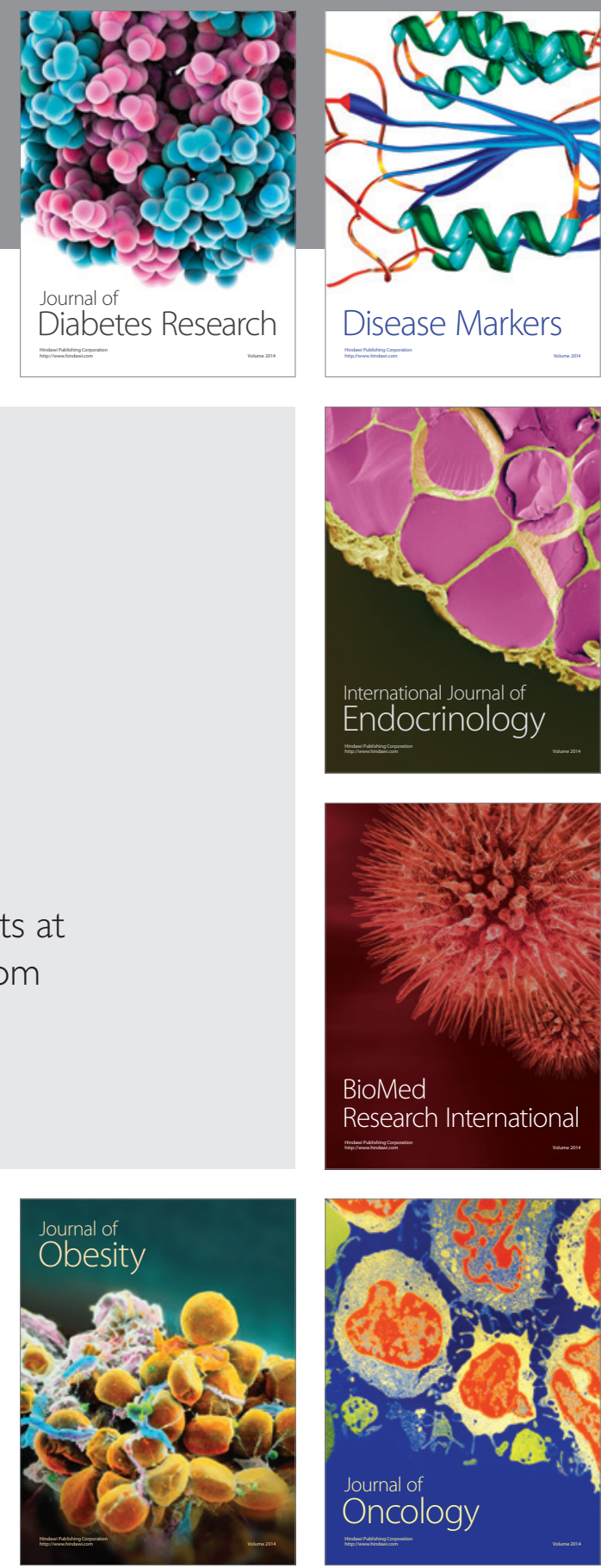

Disease Markers
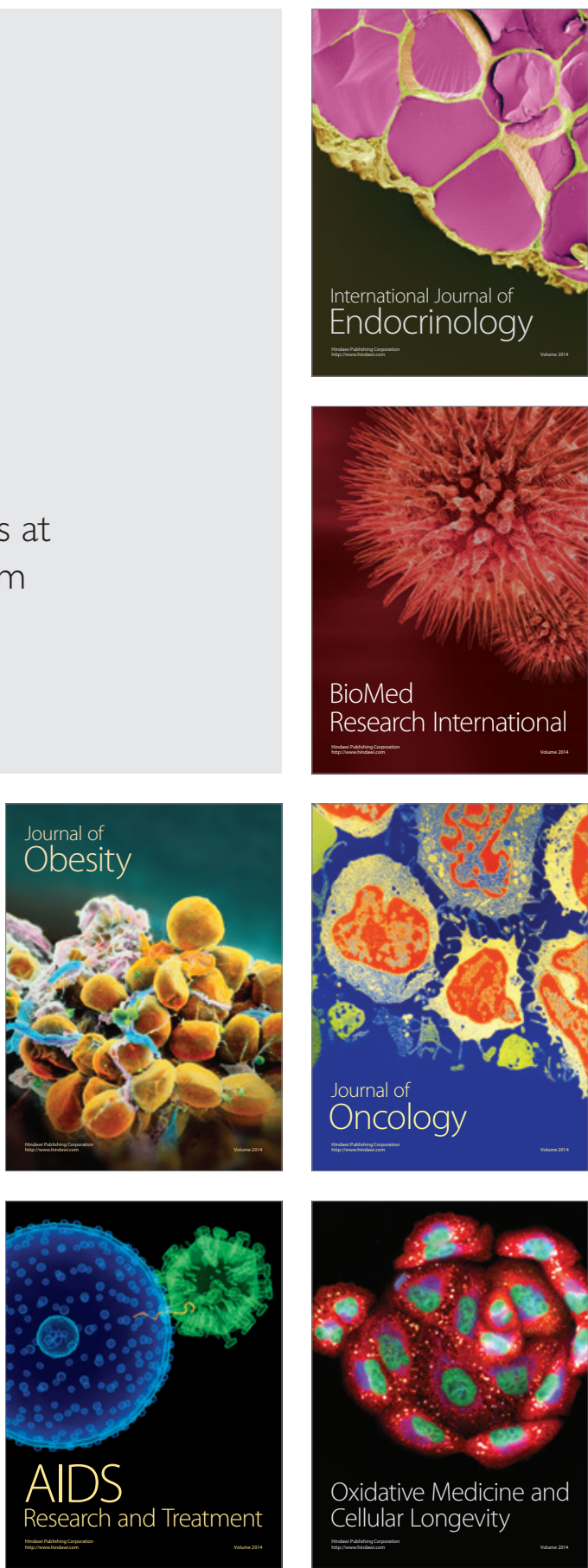